\title{
초기 뇌졸중 환자에서 체간 제한과 결합된 로봇 보조 상지 훈련의 효과: 무작위 대조 예비 연구
}

\author{
정경만 ${ }^{1}$, 정유진 ${ }^{* 2}$ \\ '원광대학교병원 물리치료실, ${ }^{2}$ 원광대학교병원 작업치료실
}

The Effect of Robot-Assisted Upper Limb Training Combined with Trunk Restraint in Early Stroke Patients: Randomized Controlled Pilot Study

\author{
Kyeoung-Man Jung ${ }^{1}$, Yu-Jin Jung ${ }^{*}$ \\ ${ }^{1}$ Dept. of physical Therapy, Won-kwang University Hospital \\ ${ }^{* 2}$ Dept. of occupational Therapy, Won-kwang University Hospital
}

Purpose This study was to determine the effect of robot-assisted upper limb training combined with trunk restraint in early stroke patient. Methods Sixteen inpatients were randomly allocated into the experimental group ( $\mathrm{n}=8)$, who received robot-assisted upper limb training combined with trunk restraint, and the control group ( $\mathrm{n}=8$ ), who received a robot-assisted upper limb training. Each intervention consisted of a 30 min session once a day, five times a week, for four weeks. To measure the functions of the upper limbs and performance capacities in the activities of daily living, the Fugl-Meyer assessment-upper extremity (FMA-UE), Manual function test (MFT), Korean-modified Barthel index (K-MBI) were used before after the intervention. Results The robot-assisted upper limb training combined with trunk restraint group and control group improved more significantly after intervention in FMA, MFT, K-MBI (p<.05). However, robot-assisted upper limb training combined with trunk restraint group was more effective than control group in increasing the FMA, MFT, K-MBI $(\mathrm{p}<.05)$. Conclusion These results suggest that robot-assisted upper limb training combined with trunk restraint is more helpful to improve upper-extremity function than robot-assisted upper limb training only early stroke patients.

Key words Activities of daily living, Robot-assisted upper limb training, Stroke, Trunk restraint, Upper extremity function Corresponding author Yu-Jin Jung (amyeugene@naver.com)
Received date
23 August 2017
Revised date
20 September 2017
Accepted date
19 October 2017

\section{I. 서 론}

뇌졸중은 뇌혈관 질환으로 뇌로 공급되는 혈관이 막히거나 터 짐으로써 신체 전반에 걸쳐 기능 제한과 일상생활활동에 장애 를 유발한다. ${ }^{1)}$ 뇌졸중 환자의 $85 \%$ 에서 인지, 운동, 감각, 균형 장애 등이 나타나며 그 중 $69 \%$ 이상의 환자에서 마비측 상지 에 기능 장애가 발생된다. ${ }^{2)}$ 특히 뇌졸중 발병 초기에 마비측 상지의 심각한 운동장애를 보이는 환자 중 $20 \%$ 정도에만 상지 기능이 일부 회복되었고, 상지 기능이 완전 회복되는 경우는 $5 \%$ 미만이라고 하였으며, 발병 5 년 이후에도 $25 \%$ 의 환자가 적절한 상지 사용의 어려움을 호소할 정도로 뇌졸중 후 상지 기능 회복은 부정적이다. ${ }^{3,4)}$

doi : http:dx.doi.org/10.17817/2017.10.16.111179
뇌졸중 이후 발생하는 상지 기능 장애는 정교한 손동작, 조 작하기, 식사하기, 글씨 쓰기, 개인 위생관리, 의사표현하기, 걷 기, 균형 유지하기 등과 같이 동작을 방해하는 주요 원인으로 작용하기 때문에 환자의 사회적 독립성을 방해하고 삶의 질 저 하를 초래한다. ${ }^{5)}$ 뇌졸중 환자의 상지 기능 회복은 인간의 가장 기본적 삶을 유지하는데 중요하기 때문에 하지의 보행 기능 못 지않게 중요하다고 할 수 있다. ${ }^{6)}$ 최근 무작위 대조군 연구를 통한 메타 분석한 연구에서, 상지 기능 향상을 위해 실시한 상 지 재활 로봇 치료가 상지 근력 및 운동 기능에 효과적이라는 보고가 있었다. ${ }^{7)}$

상지 로봇은 신경학적 질환이 있는 환자들에게 감각 운동 훈련을 제공할 수 있는 장비로, 상지 무게를 보조하여 비 정상 적인 골곡근 시너지를 감소시켜 선택적 움직임을 유도할 수 있 으며, 과제 지향적 훈련을 통해 운동 학습 및 동기유발을 증진 
할 수 있는 장점이 있다. ${ }^{8)}$ 그러나 아직까지 선행 연구마다 상지 로봇 치료 효과에 대한 결과 차이가 나타나고 있는데 이는 적용 한 로봇의 종류, 로봇 치료를 시작한 시점, 치료의 강도나 적용 기간, 환자의 인지 상태 등이 그 원인이라고 하였다. ${ }^{9)} \mathrm{JoO}$ 등 $(2014)^{10)}$ 은 아급성기 뇌졸중 환자를 대상으로 상지 로봇 치료 를 실험군에 적용하고 대조군에는 고식적 치료만 시행한 결과 두 군간 상지 기능과 일상생활활동에 차이가 없었다고 하였다.

기존 연구에서 보면, 뇌졸중 환자의 상지 훈련 시 신체 다 른 부위에서 상지의 부족한 움직임을 보상하기 위한 다양한 형 태의 보상 움직임이 발생된다고 하였다. ${ }^{11)}$ 이러한 의도하지 않 은 신체의 보상 움직임은 결과적으로 상지 훈련의 강도와 선택 적 동작을 방해하는 요인으로 작용하여 상지 훈련의 효과를 감 소시키기 때문에 상지 훈련 시 보상 움직임을 억제하기 위한 체간 움직임의 제한은 상지 훈련의 효과를 향상 시킬 수 있다 고 하였다. ${ }^{12)}$ 체간 제한 방법은 마비측 상지로 과제 수행 시 어깨관절, 주관절의 부족한 움직임을 보상하기 위한 체간의 움 직임을 감소시킴으로써 상지 기능에 영향을 미칠 수 있다. ${ }^{13)}$ 체간의 과도한 움직임을 억제하여 보상 움직임을 줄이면 상지 운동 시 더 많은 잠재적 기능 회복을 유도할 수 있다. ${ }^{14)}$

그러나 대부분의 로봇 보조 상지 훈련 시 체간의 과도한 움직임을 제한하여 시행한 연구는 전무한 실정이다. 따라서 본 연구에서는 초기 뇌졸중 환자를 대상으로 체간 제한과 결합된 로봇 보조 상지 훈련이 상지 운동 기능과 일상생활동작에 미치 는 효과를 알아보고자 하였다.

\section{II. 연구방법}

\section{1. 연구 대상 및 연구기간}

본 연구는 2016년 9월 1일부터 2016년 12월 30일까지 전북 익산에 위치한 $\mathrm{W}$ 대학교병원 재활의학과에 입원치료 중인 뇌졸 중 환자 16명을 대상으로 실시하였다. 연구대상자는 본 연구의 선정조건에 부합되는 자로 본 연구의 목적과 절차에 대한 충분 한 설명을 듣고 실험 참여에 자발적으로 서면 동의한 자를 대 상으로 하였다. 대상자의 선정 기준은 뇌졸중으로 진단 받은 지 1 개월 미만인 환자 중 재발되지 아니한 자, 마비측 어깨관 절 굴곡근과 외전근이 도수근력 측정(manual muscle test, $\mathrm{MMT}$ ) 상 Poor 이상인 자, 상지 경직의 등급이 $\mathrm{MAS}$ (modified ashworth scale)가 2 미만인 자, 한국형 간이정신 상태검사 판별검사 MMSE-K(mini-mental state examinationKorea) 점수가 24점 이상인 자로 하였으며, 로봇 치료를 적절 히 수행할 수 없는 기저질환이 있는 자는 제외하였다. 대상자 는 다음과 같다(Table 1).

\section{2. 측정 도구 및 측정 방법}

1) Fugl-Meyer 평가 척도 (Fugl-Meyer Assessment; FMA) Fugl-Meyer 평가 척도는 뇌졸중 환자를 대상으로 운동기능, 균형 감각, 관절 가동범위 등 운동기능 회복단계를 양적으로 평가하기 위해 개발된 측정 도구이다. ${ }^{15)}$ 상지와 하지 두 영역 으로 나뉘어 있고 공동운동(synergy)을 고려하여 평가할 수 있다. 본 연구에서 사용한 상지 영역의 세부 항목은 어깨/팔꿈 치/아래팔 18항목, 손목 5항목, 손(손가락) 7항목, 상지 협응 능력 3항목 이었다. 마비측과 비마비측을 3회씩 실시하여 높은 점수를 채택하며, 수행 정도에 따라 0 2점을 부여하게 된다(0 점은 수행할 수 없음, 1 점은 부분적으로 수행, 2점은 완전하게 수행). 상-하지 모두 포함한 전체 점수는 100 점으로 상지에 해 당하는 검사는 33항목으로 최대 66점이며, 회복 정도를 백분 율로 나타낼 수도 있다. ${ }^{16)}$ 측정자 간 신뢰도와 측정자 내 신뢰 도는 .94와 .99로 높은 신뢰도를 가지고 있다. ${ }^{17)}$

\section{2) 상지 기능 검사(Manual Function TEST; MFT)}

뇌졸중 환자의 상지 운동기능의 전반적인 상태를 평가하기 위 해 일본 동북 대학 의학부 리하연구소에서 개발한 검사도구이 다. 뇌졸중 환자의 상지 기능 및 동작 능력 측정을 짧은 시간 에 측정할 수 있는 장점이 있다. 검사 항목으로는 상지 운동 4 항목, 파악 2항목, 손가락 조작 2항목으로 상지 운동 기능의 회복 상태를 확인 할 수 있다. 세부 항목마다 수행 시 1점, 불 가능할 시 0점으로 기록하는데 어깨 굽힘(4점), 어깨 벌림(4 점), 후두부에 손 닿기(4점), 등에 손 닿기(4점), 쥐기(3점), 집 기(3점), 입방체 운반(4점), 페그 보드에 꽂기(6점)으로 총점은 32 점이 만점이다. ${ }^{18)}$ 검사자간 신뢰도와 검사-재검사 신뢰도는 .95 으로 높게 보고되고 있다. ${ }^{19)}$

3) 한국판 수정된 바델 지수(Korean version of modified Barthel index; K-MBI)

일상생활활동 수행능력을 평가하기 위한 도구로 개발된 K-MBI 는 Shah 등(1989) ${ }^{20)}$ 이 개정한 $\mathrm{MBI}$ 제5판을 한국 실정에 맞 도록 일부 문항을 수정 및 보완하여 표준화 한 것이다. 총 10 가지의 일상생활 활동 항목으로 구성되어 있으며 각 항목별 5 점 척도로 점수화 시킨다. 100점 만점으로 0 24점은 완전 의 존, 25 49점은 중등도 의존, 50 74점은 중도 의존, 75 90점 은 경도 의존, 91 99점은 최소 의존, 100 점은 완전 독립성을 나타낸다. 검사-재검사 신뢰도는 .89, 검사자 간 신뢰도는 .95 로 높게 보고되고 있다. ${ }^{21)}$

\section{3. 치료 중재}

본 연구에서 로봇 보조 상지 훈련은 ArmeoSpring (Hocoma Inc, Zurich, Switzerland)를 이용하였다. 로봇 훈련은 해당 
회사로부터 로봇사용 방법에 대한 교육을 이수하고 자격증을 부여 받은 경력 5년 이상의 작업 치료사가 시행하였다. 훈련 전 환자 및 보호자에게 훈련에 대한 충분한 설명과 주의사항을 교육 한 후 손잡이 위치, 하부 팔의 길이, 상부 팔의 길이를 조 정하여 마비측 팔을 로봇 외골격에 부착하였다. 훈련 프로그램 은 마비측 상지의 뻗기, 들어 올리기, 옮기기, 이동 시키기 등 전반적인 일상생활과 관련된 동작을 위주로 개인의 능력과 목 적에 맞게 설정하였으며, 난이도는 환자의 운동 수행 결과를 토대로 결정하였다. 로봇 보조 상지 훈련 중 실험군은 체간의 전방이동과 회전 등의 보상적 움직임을 최소화 하기 위해 길이 $1.5 \mathrm{~m}$ 스트랩으로 체간을 고정 시켜 훈련 시 체간의 움직임을 제한 하였다(Figure 1). 대조군은 체간을 따로 고정하지 않고 등받이에 부착한 상태로 자유롭게 훈련 하도록 하였다(Figure 1). 운동의 강도는 운동자각도를 이용하여 1 2주차에서는 RPE 13 14(약간 힘들다), 3 4주에서는 RPE 14 15(힘들다)로 상 향 조절 하였다. 훈련은 1 일 30 분, 주 5 회, 4 주간 총 20 회를 시행 하였다.

\section{4. 연구 방법}

본 연구는 총 21 명의 대상자를 모집하였으나 선정기준에 충족 하지 못한 4 명과 참여를 거부한 1 명을 제외하여 총 16 명의 급 성기 뇌졸중 환자를 대상으로 실험을 진행하였다. 대상자는 불 투명한 상자에서 실험군과 대조군이 적혀있는 동봉된 봉투를
뽑아 체간 제한과 결합된 로봇 보조 상지 훈련을 시행하는 실 험군(8명)과 로봇 보조 상지 훈련을 시행하는 대조군(8명)으로 무작위 배정하였다. 중재 전 사전평가와 중재 후 사후평가는 5 년 이상의 임상경력을 가진 동일한 작업치료사가 실시하였다. 실험에 참가한 모든 대상자는 일반적 물리치료와 작업치료를 실시하였고, 전반적인 연구 절차는 다음과 같다(Figure 2).

\section{5. 분석 방법}

본 연구에서 수집된 자료는 SPSS ver. 19.0 (SPSS Inc., Chicago, IL, USA) 통계 프로그램을 이용하여 분석 하였다. 중재 전 연구 참여자의 일반적 특성은 기술통계량을 이용해 평 균과 표준편차를 제시하였고, 명목척도는 카이제곱 검정과 순 서척도는 맨 휘트니(Mann-Whitney) U 검정을 통해 동질성 검정을 실시하였다. 군 간 비교를 위해서 맨 휘트니 (Mann-Whitney) U 검정을 이용하였고, 군 간 중재 전후를 비교 하기 위해서 비모수 검정 방법인 윌콕슨 부호순위 (Wilcoxon Signed-ranks) 검정을 이용하였고, 두 군별 중재 전후 변화량을 비교하기 위해 맨 휘트니(Mann-Whitney) U 검정을 이용하였다. 통계적 유의 수준 $\mathrm{p}$ 값은 .05로 하였다.
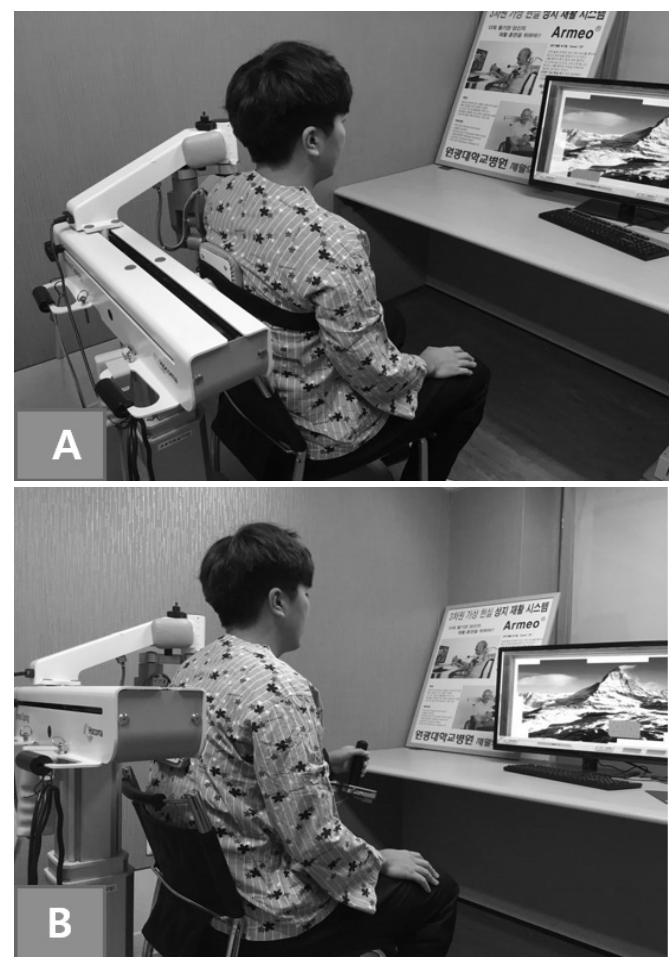

Figure 1. (A) Experimental group (B) Control group

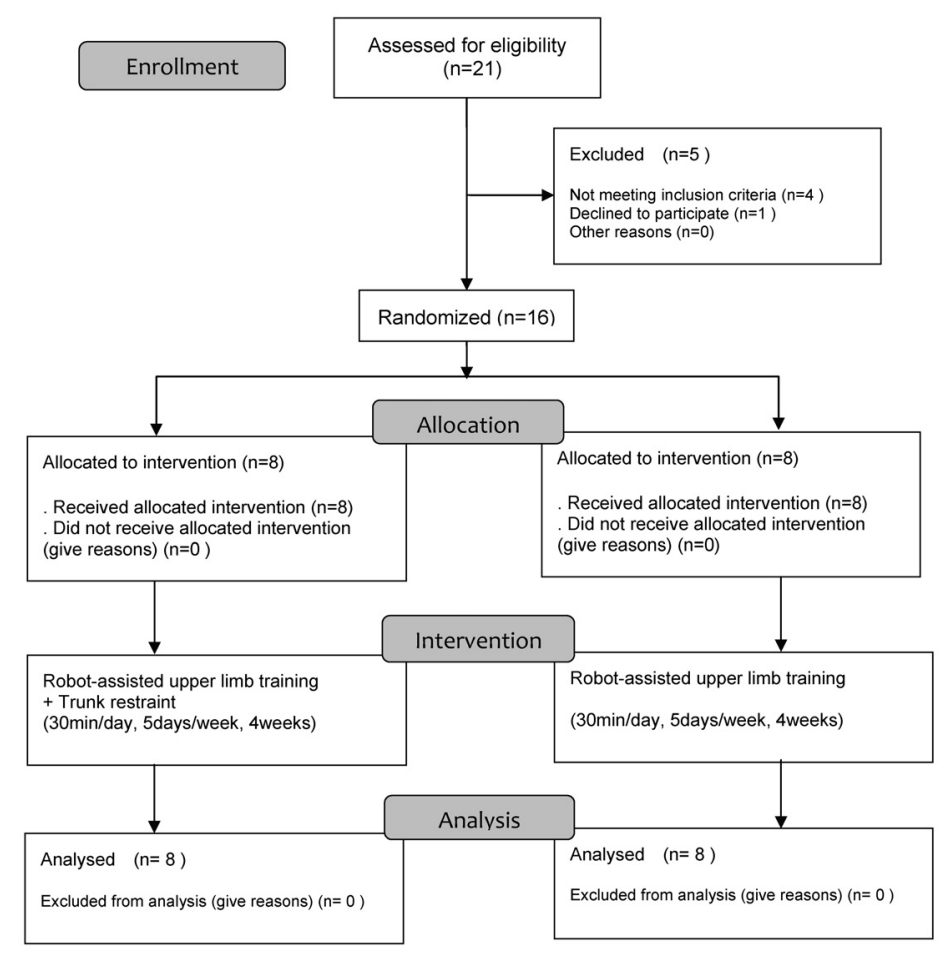

Figure 2. Flowchart of the study process 
Table 3. Results of between-group comparison in the change value of each parameter of subjects

\begin{tabular}{cccc} 
& $\begin{array}{c}\text { RAULT }^{\mathrm{a}}+\mathrm{TR}^{\mathrm{b}} \\
\text { (n=8) }\end{array}$ & $\begin{array}{c}\text { RAULT group } \\
\text { (n=8) }\end{array}$ & Z(P) \\
FMA-UE $^{\mathrm{c}}$ (score) & $18.62 \pm 2.55^{\mathrm{d}}$ & $14.19 \pm 5.41$ & $-3.263\left(.001^{*}\right)$ \\
MFT $^{\mathrm{e}}$ (score) & $11.12 \pm 1.88$ & $9.00 \pm 2.63$ & $-3.411\left(.001^{*}\right)$ \\
K-MBIf $^{\mathrm{f}}$ (score) & $27.25 \pm 5.94$ & $21.00 \pm 7.84$ & $-3.368\left(.001^{*}\right)$ \\
\hline
\end{tabular}

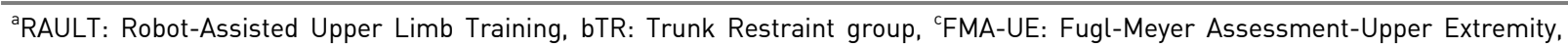

${ }^{d}$ Mean \pm Standard deviation, ${ }^{e}$ MFT: Manual Function Test, ${ }^{f} \mathrm{~K}-\mathrm{MBI}$ : Korean version of modified Barthel index, ${ }^{*} \mathrm{p}<.05$

\section{III. 결과}

\section{1. 연구대상자의 일반적 특성}

본 연구에 참여한 대상자는 총 16 명으로 실험군 8 명, 대조군 8
명이다. 실험군은 남자5명, 여자 3 명이며, 손상측은 왼쪽 3 명, 오른쪽 5명으로 평균 연령은 61.86세이고, 유병 기간은 평균 18.91일 이었다. 대조군은 남자 6명, 여자 2명이며, 손상측은 왼쪽 4 명, 오른쪽 4 명으로 평균 연령은 62.57 세이고, 유병 기

Table 1. General characteristics of subjects

\begin{tabular}{|c|c|c|c|}
\hline \multirow[b]{2}{*}{ Characteristics } & \multicolumn{2}{|c|}{ Pre-treatment } & \multirow[b]{2}{*}{$\chi^{2} / z(P)$} \\
\hline & RAULT $^{\mathrm{a}}+\mathrm{TR}^{\mathrm{b}}$ group $(\mathrm{n}=8)$ & RAULT group ( $n=8)$ & \\
\hline Gender (male/female) & $5 / 3$ & $6 / 2$ & $1.14(.49)$ \\
\hline Affected side (left/right) & $3 / 5$ & $4 / 4$ & $.291(.69)$ \\
\hline Onset duration (day) & $18.91 \pm 1.89^{c}$ & $19.88 \pm 1.84$ & $-.192(.74)$ \\
\hline Age (year) & $61.86 \pm 9.17$ & $62.57 \pm 5.62$ & $-.263(.69)$ \\
\hline Body weight $(\mathrm{kg})$ & $62.93 \pm 9.75$ & $63.91 \pm 8.46$ & $-.061(.84)$ \\
\hline MMSE-K $^{\mathrm{d}}$ (score) & $25.86 \pm 2.77$ & $25.71 \pm 1.75$ & $-1.331(.48)$ \\
\hline
\end{tabular}

${ }^{\mathrm{a}}$ RAULT: Robot-Assisted Upper Limb Training, ${ }^{\mathrm{b}}$ TR: Trunk Restraint group, ${ }^{\mathrm{c}}$ Mean \pm Standard deviation, ${ }^{\mathrm{d}}$ MMSE-K: Mini-Mental State Examination-Korea, ${ }^{*} p<.05$

Table 2. Results of between-group and within-group comparison on FMA, MFT, K-MBI

\begin{tabular}{|c|c|c|c|c|}
\hline & & $\begin{array}{c}\mathrm{RAULT}^{\mathrm{a}}+\mathrm{TR}^{\mathrm{b}} \text { group } \\
(\mathrm{n}=8)\end{array}$ & $\begin{array}{l}\text { RAULT group } \\
\text { (n=8) }\end{array}$ & $\mathrm{Z}(\mathrm{P})$ \\
\hline \multirow[t]{4}{*}{ FMA-UE $^{\mathrm{C}}$} & (score) & & & \\
\hline & Pre-test & $16.00 \pm 2.13^{\mathrm{d}}$ & $16.62 \pm 2.26$ & $-.371(.711)$ \\
\hline & Post-test & $34.62 \pm 3.42$ & $26.37 \pm 3.11$ & $-3.11\left(.002^{*}\right)$ \\
\hline & $z(p)$ & $-2.527\left(.012^{*}\right)$ & $-2.524\left(.012^{*}\right)$ & \\
\hline \multirow[t]{4}{*}{$\mathrm{MFT}^{\mathrm{e}}$} & (score) & & & \\
\hline & Pre-test & $13.12 \pm 2.53$ & $11.50 \pm 2.00$ & $-1.333(.183)$ \\
\hline & Post-test & $24.25 \pm 3.53$ & $18.50 \pm 1.85$ & $-2.967\left(.003^{*}\right)$ \\
\hline & $z(p)$ & $-2.539\left(.011^{*}\right)$ & $-2.549\left(.012^{*}\right)$ & \\
\hline \multirow[t]{4}{*}{$\mathrm{K}-\mathrm{MBI}{ }^{\mathrm{f}}$} & (score) & & & \\
\hline & Pre-test & $29.75 \pm 4.86$ & $28.87 \pm 4.38$ & $-.369(.712)$ \\
\hline & Post-test & $57.00 \pm 3.58$ & $43.62 \pm 5.57$ & $-3.21\left(.001^{*}\right)$ \\
\hline & $z(p)$ & $-2.52\left(.012^{*}\right)$ & $-2.527\left(.022^{*}\right)$ & \\
\hline
\end{tabular}

${ }^{\mathrm{a}} \mathrm{RAULT}$ : Robot-Assisted Upper Limb Training, ${ }^{\mathrm{b}} \mathrm{TR}$ : Trunk Restraint group, ${ }^{\mathrm{C}}$ FMA-UE: Fugl-Meyer Assessment-Upper Extremity,

${ }^{\mathrm{d}}$ Mean \pm Standard deviation, ${ }^{\mathrm{e}} \mathrm{MFT}$ : Manual Function Test, ${ }^{\mathrm{f}} \mathrm{K}-\mathrm{MBI}$ : Korean version of modified Barthel index, ${ }^{*} p<.05$ 
간은 평균 19.88 일 이었다. 중재 전 두 군간 일반적 특성에 대 한 동질성 검증을 실시한 결과 통계학적 유의한 차이가 없었다 (p>.05)(Table 1).

\section{2. 두 군간 중재 전·후 상지 기능, 일상생활활동 수행능력 수 준 비교}

두 군에서 중재 전에 측정된 $\mathrm{FMA}, \mathrm{MFT}, \mathrm{K}-\mathrm{MBI}$ 점수들은 동 질성 검사에서 유의한 차이가 없었다(p>.05)(Table 2). 두 군 간 중재 후 결과 비교에서, 두 집단 모두에서 측정된 $\mathrm{FMA}$, $\mathrm{MFT}, \mathrm{K}-\mathrm{MBI}$ 에서 모두 유의한 차이가 나타났다 $(\mathrm{p}<.05)$ (Table 2).

\section{3. 두 군간 중재에 따른 상지 기능, 일상생활활동 수행능력 변 화량 비교}

중재 후 두 군간의 상지 기능(FMA, MFT), 일상생활동작 수행 력(K-MBI)의 변화량의 결과 비교에서, 체간 제한과 결합된 로 봇 보조 상지 훈련군이 로봇 보조 상지 훈련군 보다 유의하게 더 큰 차이값을 갖는 것으로 나타났다 $(\mathrm{p}<.05)($ Table 3$)$.

\section{IV. 고 찰}

본 연구는 목적은 급성기 뇌졸중 환자를 대상으로 체간 제한과 결합된 로봇 보조 상지 훈련이 상지기능, 일상생활동작 수행능 력에 미치는 효과를 알아보기 위한 것이었다. 이를 위해 본 연 구에 참여한 급성기 뇌졸중 환자를 대상으로 실험군에는 체간 제한과 결합된 로봇 보조 상지 훈련을, 대조군에는 로봇 보조 상지 훈련을 30 분씩 1 일 1 회 적용하였다. 본 연구의 결과 체 간 제한과 결합된 로봇 보조 상지 훈련이 로봇 보조 상지 훈련 보다 상지 기능, 일상생활동작 향상에 더 효과적인 것으로 나 타났다. 따라서 뇌졸중으로 인한 체간 제한과 결합된 로봇 보 조 상지 훈련은 상지 기능과 일상생활활동 능력에 효과성이 입 증 되었다. 본 연구에서는 사용된 체간 제한과 결합된 로봇 보 조 상지 훈련 프로그램은 마비측 상지를 사용해서 모니터에 나 오는 과제를 수행하는 동안 체간의 보상 운동을 억제하여 마비 측 상지가 더 많이 사용될 수 있도록 하였다. ${ }^{22)}$

상지 기능 수준을 알아보는 FMA와 MFT 검사 상 체간 제 한과 결합된 로봇 보조 상지 훈련군은 로봇 보조 상지 훈련군 보다 더 큰 개선을 보였다. Michaelsen 등(2006) ${ }^{22)}$ 은 뇌졸 중 환자를 대상으로 실험군에 체간 제한을 겸한 상지 운동을 적용한 결과 체간 제한을 하지 않은 대조군에 비해 기능과 손 상의 정도가 더 개선됨을 확인 하였다. 이러한 결과는 체간이
제한됨으로 상지 운동 시 능동 관절 범위가 증가하였기 때문이 라고 하였다. $\operatorname{Kim}$ 등 $(2015)^{23)}$ 은 뇌졸중 환자를 대상으로 로 봇 보조 상지 재활 훈련을 시행한 실험군에서 상지 기능의 신 경학적 회복 및 일상생활동작의 호전에 유의한 변화를 확인 하 였으며, 고강도 훈련이 효율적인 치료를 위해 고려되어야 한다 고 하였다. 본 연구의 중재에서도 선행연구에서 적용한 로봇 보조 상지 훈련과 체간 제한 중재를 결합하였고, 연구 결과 선 행 연구와 유사한 결과가 나타났다.

본 연구의 결과는 다음과 같은 신경학적 요인에 의해 개선 된 것으로 추측해 볼 수 있는데, 첫째, 로봇 보조 재활 훈련을 통해 환측의 상지만을 집중적으로 훈련 할 수 있어 마비측 상 지의 사용 기회를 증가시켰으며, ${ }^{24)}$ 둘째, 뇌 손상 후 과제 지향 적인 고강도 반복훈련을 통해 대뇌피질 수준에서의 재조직화 과정이 촉진되어 상지 기능 향상에 기여할 수 있었다. ${ }^{25)}$ 셋째, 뇌졸중 이후 재활과정에서 이뤼지는 집중적인 과제 지향 훈련 은 기능적 향상으로 이어질 수 있는 중재 방법의 기초가 된 다. ${ }^{26)}$ 본 연구의 결과로 체간 제한과 결합된 로봇 보조 상지 훈련이 체간의 보상 작용을 감소시켜 환측 상지를 더 사용함으 로써 상지 기능이 더 향상된 것으로 생각된다.

뇌졸중 환자는 과도한 보상작용, 강직, 근 약화, 비마비측 상지의 사용으로 마비측 상지의 사용빈도가 감소되므로 마비측 상지 기능이 더욱 감소하게 된다. ${ }^{27)}$ 이러한 요소는 상지 움직 임 시 어깨관절 근위부의 굴곡 시너지를 유발해 팔 뻗기 동작 시 주관절의 가동성을 제한 시켜 상지 기능을 제한하게 된다. 특히 상지의 일상생활동작과 관련해서 어깨관절 굴곡과 주관절 의 신전 각도는 중요한 요소가 될 수 있으므로 이러한 동작을 유도할 수 있는 다양한 훈련은 중요하다고 할 수 있다. ${ }^{28)}$ 본 연구에서도, 실험군과 대조군 모두 상지 기능과 일상생활활동 수행능력이 증가하였다. 그러나 로봇 보조 훈련 시 체간을 자 연스럽게 움직일 수 있도록 한 대조군에 비해 체간 제한과 결 합된 실험군의 로봇 보조 훈련 결과 일상생활활동 수행능력이 더 크게 향상된 것으로 나타났다. 이는 과도한 체간 보상 움직 임이 상지의 잠재적인 사용 기회를 감소시키기 때문에 체간의 움직임을 제한시켜 팔뻗기와 주관절 신전과 같은 상지의 순수 한 움직임을 유도할 수 있었기 때문에 일상생활활동 수행능력 이 향상된 것으로 생각된다. 또한, 근력 약화로 중력에 대항하 여 독립적인 상지 기능 훈련이 어려운 환자에게 상지 로봇을 사용하면, 팔의 무게가 로봇에 의해 지지되어 중력에 대한 부 담이 줄어들면 상지 훈련 시 불수의적인 굴곡 시너지가 감소로 선택적인 움직임이 촉진되어 상지 기능이 향상되었고, 추가적 인 체간 움직임의 제한은 체간의 보상작용을 최소화 시켜 상지 만을 이용한 노력이 증가되었기 때문인 것으로 생각된다.

그러나, 본 연구의 제한점으로는 첫째, 연구의 대상자의 수 가 16 명으로 뇌졸중 환자 전체에 일반화 하는 것은 어려움이 
있지만, 예비 연구로 진행되었기 때문에 향후 연구에서는 연구 대상자의 표본 크기를 산출하여 연구가 진행되어야 할 것이다. 둘째, 장기간의 추적 관찰을 통해 중재 이후에 치료적 효과의 지속성을 확인하지 못하였다. 향후 연구에서는 이러한 제한점 을 보완하여 더 많은 연구가 진행되어야 할 것으로 생각된다.

\section{V. 결 론}

본 연구는 16 명의 급성기 뇌졸중 환자를 대상으로 체간 제한 과 결합된 로봇 보조 상지 훈련이 상지 기능과 일상생활활동 수행능력에 미치는 효과를 알아보기 위해 실시되었다. 대상자 들을 실험군 8명과 대조군 8명으로 무작위 배정 후 실험군은 체간 제한과 결합된 로봇 보조 상지 훈련을 실시하였고, 대조 군은 로봇 보조 상지 훈련을 실시하였다. 본 연구의 결과 두 군 모두 중재 후 상지 기능을 알아본 FMA, MFT와 일상생활 활동 수행능력을 알아본 K-MBI가 향상되었지만, 변화량의 차 이에서는 실험군이 대조군에 비해 더 큰 향상을 보였다. 따라 서 본 연구의 결과 체간 제한과 결합된 로봇 보조 상지 훈련은 급성기 뇌졸중 환자의 상지 기능과 일상생활활동 수행능력을 개선하는데 효과적임을 확인하였다. 향후 로봇 보조 상지 훈련 시 효과적인 중재 방법으로 사용될 수 있을 것이다.

\section{References}

1. Masiero S, Celia A, Rosati G, et al. Robotic-assisted rehabilitation of the upper limb after acute stroke. Arch Phys Med Rehabil. 2007;88(2):142-9.

2. Luke C, Dodd KJ, Brock K. Outcomes of the Bobath concept on upper limb recovery following stroke. Clin Rehabil. 2004;18(8):888-98.

3. Geddes JM, Fear J, Tennant A, et al. Prevalence of self reported stroke in a population in northern England. J Epidemiol Community Health. 1996;50(2):140-3.

4. Hayward K, Barker R, Brauer S. Interventions to promote upper limb recovery in stroke survivors with severe paresis: a systematic review. Disabil Rehabil. 2010;32(24):1973-86.

5. Michaelsen SM, Dannenbaum R, Levin MF. Task-specific training with trunk restraint on arm recovery in stroke. Stroke. 2006;37(1):186-92.

6. Sheng B, Lin M. A longitudinal study of functional magnetic resonance imaging in upper-limb hemiplegia after stroke treated with constraint-induced movement therapy. Brain inj. 2009;23(1):65-70.

7. Mehrholz J, Platz T, Kugler J, et al. Electromechanical and robot-assisted arm training for improving arm function and activities of daily living after stroke. Cochrane Database Syst Rev. 2008;4(4):CD006876.

8. Sale P, Franceschini M, Mazzoleni, et al. Effects of upper limb robot-assisted therapy on motor recovery in subacute stroke patients. J Neuroeng Rehabil. 2014;11(1):104.

9. Jung YJ, Jung KM, Joo MC. Effects of Robot-Assisted upper limb training in patients with acute stroke: Randomized Controlled Pilot Study. KSOT. 2017;25(2): 15-27.

10. Joo MC, Park HI, Noh SE, et al. Effects of robot-assisted arm training in patients with subacute stroke. Brain \& Neurorehabilitation. 2014;7(2):111-17.

11. Cirstea MC, Ptito A, Levin MF. Arm reaching improvements with short-term practice depend on the severity of the motor deficit in stroke. Exp Brain Res. 2003;152(4):476-88.

12. Michaelsen SM, Dannenbaum R, Levin MF. Task-specific training with trunk restraint on arm recovery in stroke: randomized control trial. Stroke. 2006;37(1):186-92.

13. Cirstea MC, Levin MF. Compensatory strategies for reaching in stroke. Brain. 2000;123(5): 940-53.

14. Choudhary A, Gulati S, Kabra M, et al. Efficacy of modified constraint induced movement therapy in improving upper limb function in children with hemiplegic cerebral palsy: a randomized controlled trial. Brain Dev. 2013;35(9):870-6.

15. Fugl-Meyer AR, Jääskö L, Leyman I, et al. The post-stroke hemiplegic patient. 1. a method for evaluation of physical performance. Scand J Rehabil Med. 1975;7(1):13-31.

16. Duncan PW, Goldstein LB, Horner RD, et al. Similar motor recovery of upper and lower extremities after stroke. Stroke. 1994;25(6):1181-8.

17. Sanford J, Moreland J, Swanson LR, et al. Reliability of the Fugl-Meyer assessment for testing motor performance in patients following stroke. Phys Ther. 1993;73(7):447-7.

18. Nakamura R, Moriyama S. Manual function test (MFT) and functional occupational therapy for stroke patients. Tokorozawa, Japan: National Rehabilitation Center for the Disabled. 2000

19. Miyamoto S, Kondo T, Suzukamo Y, et al. Reliability and validity of the Manual Function Test in patients with stroke. Am J Phys Med Rehabil. 2009;88(3):247-55. 
20. Shah S, Vanclay F, Cooper B. Improving the sensitivity of the Barthel Index for stroke rehabilitation. J Clin Epidemiol. 1989;42(8):703-9.

21. Granger CV, Albrecht GL, Hamilton BB. Outcome of comprehensive medical rehabilitation: measurement by PULSES profile and the Barthel Index. Arch Phys Med Rehabil. 1979;60(4):145-54.

22. Michaelsen SM, Dannenbaum R, Levin MF. Task-specific training with trunk restraint on arm recovery in stroke: randomized control trial. Stroke. 2006;37(1):186-92.

23. Kim JS, Park SW, Lee YS, et al. Clinical outcomes of robot-assisted arm rehabilitation in stroke patients. Brain \& Neurorehabilitation. 2015;8(1):46-52.

24. Reinkensmeyer DJ. Robotic assistance for upper extremity training after stroke. Stud Health Technol Inform. 2009;145:25-39.
25. Taub E, Uswatte G, Pidikiti R. Constraint-Induced movement therapy: a new family of techniques with broad application to physical rehabilitation-a clinical review. J Rehabil Res Dev. 1999;36(3):237-51.

26. Duncan PW. Synthesis of intervention trials to improve motor recovery following stroke. Top Stroke Rehabil. 1997;3(4):1-20.

27. Taub E, Crago J, Uswatte G. Constrainted-induced movement therapy: a new approach to treatment in physical rehabilitation. Rehabil Psychol. 1989; 43:15279.

28. Brunner IC, Skouen JS, Strand LI. Is modified constraint-induced movement therapy more effective than bimanual training in improving arm motor function in the subacute phase post stroke? A randomized controlled trial. Clin Rehabil. 2012;26(12):1078-86. 
